\title{
Integrated Advance Data Storage Technology for Effective Construction Logistics Management
}

\author{
Javad Majrouhi Sardroud \\ PhD researcher, School of Civil Eng. \& Construction, Kingston University London, UK \\ K0851129@kingston.ac.uk \\ Mukesh C. Limbachiya \\ Head of School of Civil Engineering \& Construction, Kingston University London, UK \\ m.limbachiya@,kingston.ac.uk
}

\begin{abstract}
This paper presents a study on applying an integrated application of RFID, GPS and GSM technology for mobile, pervasive and ubiquitous tracking and locating of any objects in construction supply chain and logistics. Accurate and timely identification and tracking of resource are vital to operating a well managed and cost efficient construction project. RFID integrated with the GPS provides an opportunity to uniquely identify materials and to locate and track them in a real time basis using minimal or no worker input where transmission of data from the system to the central database will be carried out with the help of standard cellular phone communications networks technology such as GPRS and SMS. In this research GIS will be used for analyzing and representing collected data. The authors believe that full automation of the construction supply chain and logistics can increase the efficiency and productively and lead to reductions in project costs and time.
\end{abstract}

KEYWORDS: construction logistics, GPS, RFID.

\section{INTRODUCTION}

Logistics has been defined efficient flow and storage of goods from their point of origin to the point of consumption. It is the part of the supply chain process that plans, implements and controls the flow of goods. A supply chain is a network of retailers, distributors, transporters, storage facilities, and suppliers that are involved, through upstream and downstream linkages, in various processes and activities that produce value in the form of products and services. Supply chain management is a process used by company's to ensure that their supply chain is efficient and cost-effective and and focuses on minimizing the time taken to perform each activity, eliminating waste and optimizing response by maximizing value. Supply chain control is an integral aspect of supply chain management (Wang et al., 2007).

Supply chain control in construction generally comprises a group of companies and individuals working collaboratively in a supply network of interrelated processes or activities designed to effectively satisfy end-customer needs while rewarding all members of the supply chain (Arbulu 
and Tommelein, 2002). Supply chain control in construction is recognized to improve information flow, save costs, and support revenue-enhancing business strategy. The construction industry is extremely complex because its products are unique and individual projects generally involve several participants. Consequently, designing a formalized SCM system for the construction industry is extremely difficult. However, information technology enables effective supply chain control (Simchi-Levi et al., 2000). Information sharing is the key to supply chain success since it enables project participants to make decisions (Chopra and Meindl, 2001). The role of logistics in managing the supply chain is one of the recent paramount issues that have been a growing concern in the construction industry(ERABUILD, 2006). Construction supply chains and logistics includes the process of planning, ordering, shipping, receiving and storing, physical distribution, and related information from the point of origin to point of utilization for the reason of meeting the requirements.

Traditionally, manual data collection is slow, inaccurate, error prone and produces large amounts of paperwork. During the past few years, quite a few research projects have been conducted to investigate the opportunity to implement the use of new technologies in construction supply chains and logistics to tackle their problems. Automated approach can deliver continuous results in real-time and thereby overcome much of the inconvenience and inefficiency associated with traditional tracking practices(Torrent and Caldas, 2007). Traceability of construction materials as they move through the supply chain from the suppliers to the point of installation on sites provides significant benefits. Radio Frequency Identification (RFID) tags and its related equipment in the supply chain can generate benefits by reducing unnecessary costs in the management of the material and information flows and reducing the number of process and errors (Majrouhi Sardroud et al., 2010). In using such a system the information becomes available faster and work is more efficient(Gassel and Jansen, 2008).

Problems in poorly identifying, tracking and locating resource and in accessing the related information result in late deliveries, double-handling and misplacement of them that lead to schedule delays and increased project overall costs (Ergen et al., 2007). Therefore, an efficient supply chain management and control can reduce construction conflicts and project delay. The delivery and availability of construction resource at the right time and at the right place is very critical to obtain a successful construction project. Therefore, information concerning resource is a major issue and bad or incomplete information can create serious problems in a construction project and can significantly affect the success of projects. Moreover, delays in shipping of pieces result in wasted resources (cranes and crews) at the site and consequent delays in construction schedules (Ergen et al., 2007). In construction project accurate data is needed not only to control current projects, but also to update the historic database. Such updates will enable better planning of future projects in terms of costs, schedules, labor allocation, etc.

Given the mentioned monitoring and tracking problems above, the construction industry can benefit from the advantages of combining RF-based technologies with Geographical Information System (GIS) where RFID can be applied to collect the information by identifying resource automatically and the position of their external and internal transport vehicles (equipments) can be monitored with the help of Global Positioning System (GPS) in conjunction with GIS. The system will be used to improve and enable traceability and identification of tagged objects as 
they traverse the supply chain by connecting products, items/objects through a supply chain to central database. Therefore, the first purpose of this study is to develop an intelligent system based on RFID, GPS and Global System for Mobile Communications (GSM) technology for identification of the goods in construction supply chain, identifying its moving flow in logistics and tracking its location.

This paper demonstrates a system for rapid tracking, identifying, and locating resource in the construction phase. The approach involves the use of RFID, GPS, GSM, and GIS technology to provide real-time information at the actual construction supply chain and logistics. Most of the technologies which are used in this research are inexpensive and commercially available. This paper first reviews previous research and work that has been done by others relating to applications of RFID in construction, followed by an overview of the enabling technologies which are used in this research. Then it reveals the architecture of our integrated system for improving construction supply chain management. Conclusions are given in the end of paper.

\section{Background Review}

Locating tagged items effectively in construction supply chain and logistics can potentially facilitate great increases in productivity through efficiencies in coordination and allocation of resources. Many researchers reported that RFID can be used for tracking, locating, and identifying materials, vehicles and equipment that lead to important changes in the construction supply chain management.

In earlier research, Jaselskis et al. (1995) have summarized RFID technology and surveyed its potential applications in the construction industry including concrete processing and handling, cost coding of labor and equipment, and material control (Jaselskis et al., 1995). Another related research to using RFID technology for discrete point positioning in tracking construction vehicles with the help of GPS was conducted by Naresh and Jahren (Naresh and Jahren, 1997). Automated tracking of structural steel members with the aid of RFID technology at the construction job site studied by Furlani (Furlani and Pfeffer, 2000). In a study implemented by Jaselskis and El-Misalami (2003) RFID technology has been used to receive and keep tracking of pipe spool and hangers in a power plant project and a refinery project. Their pilot test demonstrated that RFID could increase operation efficiency by saving time and cost in material receiving and tracking, but the workers check RFID-tagged materials manually by using a handheld computer (Jaselskis and El-Misalami, 2003). Navon and Berkovich (2005) studied the use of RFID application in collecting data related to material arrivals and dispatches without information about tracking the status of goods on transit (Navon and Berkovich, 2005).

In another study, Caldas et al. (2006) investigated the use of GPS to track the position of fabricated pipe spools on lay down yards of an industrial construction project in order to improve the process and reduce the number of lost items(Caldas et al., 2006). Song et al. developed an RFID based method to automate the task of tracking, delivery, and receipt of fabricated pipe spools in lay down yards and under shipping portals(Song et al., 2006a, Song et al., 2006b). Ergen et al. (2007) conceptualized and applied the use of RFID and GPS combined with GIS technology in order to locate precast concrete components with minimal worker input in the 
storage yard, the position of a gantry crane was tracked by a GPS receiver while GPS data were written into RFID tags attached on the precast units being lifted. The authors associated the existing problems with double-handling, late delivery, and misplacement of components that lead to schedule delay and increased labor costs(Ergen et al., 2007). Kaneko et al. (2007) have developed a construction logistics system using RFID technology for finely controlling several construction sites in order to improve the transportation and handling of construction materials. The authors found that carbon dioxide emissions were reduced by using RFID technology (Kaneko et al., 2007). Jang and Skibniewski (2007) developed an Automated Material Tracking system based on ZigBee localization technology with two different types of query and response pulses (Jang and Skibniewski, 2007). Project performance data in the construction supply chain are commonly collected using traditional manual methods (Navon and Shpatnitsky, 2005). The data collection process is labor intensive, costly, and error prone; the resulting data are often kept as paper-based records, which need to be post processed into digital format for computer-based analysis ( $\mathrm{Lu}$ et al., 2009). Although, the aforesaid research has clearly proven the value and potential of using new technologies, studies focusing on detailed application of full automatic systems in construction supply chain and logistics are still scarce.

\section{A BRIEF REVIEW OF TECHNOLOGY}

Advancements in field data capture technologies, such as RFID enable collecting, storing and reusing field data accurately (i.e., without inaccurate recording of manual process), completely (i.e., without missing data), and timely (i.e., whenever needed). Automated Data Collection technologies is important in successfully controlling and managing construction projects and will meet the needs of main objectives of construction project management such as scope, quality, safety, cost and time. Some application of advanced tracking and data storage technologies in construction industry have been investigated previously e.g., (Akinci et al., 2006) and (Behzadan et al., 2008). RFID integrated with the GPS and wireless communication technologies provides an opportunity to uniquely identify materials, components, and equipments and to track and locate them using minimal or no worker input.

\section{RFID Technology}

RFID is a method of remotely storing and retrieving data by utilizing radio frequency in identifying, tracking, and detecting various objects that streamlines data acquisition and identification and can help improve the effectiveness and convenience of information flow in construction supply chain systems (Majrouhi Sardroud et al., 2009). An early, if not the first, work exploring RFID is the landmark paper by Harry Stockman, "Communication by Means of Reflected Power", Proceedings of the IRE, pp1196-1204, October 1948 (Landt, 2005). A RIFD system consists of tags (transponder) with an antenna and a reader (transceiver) with an antenna. The RFID reader acts as a transmitter/receiver and transmits an electromagnetic field that "wakes-up" the tag and provides the power required for the tag to operate(Wang et al., 2007). Figure 1 shows how RFID works, step by step. 


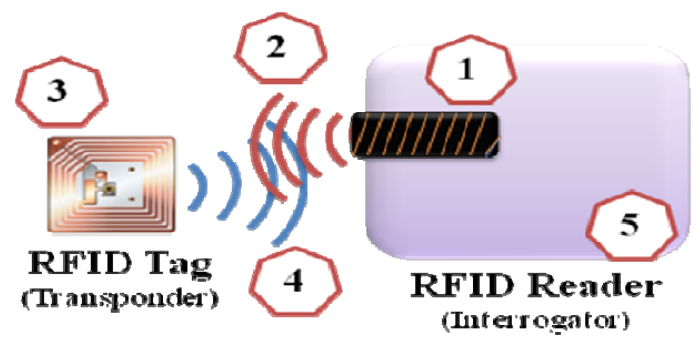

Fig. 1 RFID works, step by step

An RFID tag is a portable memory device on a chip that is encapsulated in a protective shell and can be embedded in any object and store dynamic information about the object. Tags which consist of a small integrated circuit chip coupled with an antenna to enable them to receive and respond to radio frequency queries from a reader. Tags can be categorized as read-only (RO), write once, read many (WORM) and read-write (RW) in which the volume capacity of their built-in memories varies from a few bits to thousands of bits. RFID tags can be classified into active tags (battery powered) and passive tags, which powered solely by the magnetic field emanated from the reader and hence have an unlimited lifetime. Reading and writing ranges depend on the operation frequency (low, high, ultra high and microwave). Low frequency systems generally operate at $124 \mathrm{KHz}, 125 \mathrm{KHz}$ or $135 \mathrm{KHz}$. High frequency systems operates at $13.56 \mathrm{MHz}$ and ultra high frequency (UHF) use a band anywhere from $400 \mathrm{MHz}$ to $960 \mathrm{MHz}$ (ERABUILD, 2006). Tags operating at ultra high frequency (UHF) typically have longer reading ranges than tags operating at other frequencies. Similarly, active tags have typically longer reading ranges than passive tags. Tags also vary by the amount of information they can hold, life expectancy, recycle ability, attachment method, usability, and cost. Communication distance between RFID tags and readers may decrease significantly due to interferences by steel objects and moisture in the vicinity, which is commonplace to a construction site. Active tags have internal battery source and therefore have shorter lifetime of approximately three to ten years (Jaselskis and El-Misalami, 2003). The reader, combined with an external antenna, reads/writes data from/to a tag via radio frequency and transfers data to a host computer. The reader can be configured either as a handheld or a fixed mount device(Lahiri, 2005). RFID tags are more durable and suitable for a construction site environment in comparison with Barcodes which are easily peeled off and may be illegible when they become dirty. RFID tags are not damaged as easily, does not require line-of sight for reading and writing, can be read in direct sunlight, and survive harsh conditions, reusable and permit remote. RFID technology is a promising technology for the construction industry that can be integrated into systems that can track materials, identify vehicles, and assist with cost controls (Jaselskis et al., 1995).

\section{GPS, GIS and GSM Technology}

The GPS (space-based positioning system) can provide three-dimensional position data anywhere on the earth, all weather and 24-hour to those with the proper receivers where a pair of receivers can be used in differential mode to avoid transmission interference and to get sub metric accuracy. Locations can be translated into the building's local Cartesian coordinate system for any particular area, such as a construction site (Peyret et al., 2000, Navon and 
Goldschmidt, 2002). To calculate locations, the readings from at least four satellites are necessary, because there are four parameters to calculate: three location variables and the receiver's time. The principle of differential GPS can be applied in two ways: using range measurements, called DGPS, and using phase measurements, called 'kinematic GPS'". In DGPS two receivers are used. One receiver measures the coordinates of a stationary point, called the base, whose position is perfectly known in the reference geodetic system used by GPS. The 3-D deviation between the measured and actual position of the base, which is roughly equal to the measurement error at a second receiver at an unknown point (called "rover'), is used to correct the position computed by the latter (Peyret et al., 2000). The RTK GPS can further enhance the positioning accuracy to centimetre (even millimetre) levels by combining the measurements of the signal carrier phases from both base and rover receivers with special algorithms.

Geographic Information System (GIS) is a computer-based system (a collection of computer hardware, software, and geographic data) to collect, store, integrate, manipulate, analyze, and display data in a spatially referenced environment. GIS allows us to view, understand, question, interpret, and visualize data from a variety of sources in many ways that reveal relationships, patterns, and trends in the form of maps, globes, reports, and charts. Spatial information of resource can be displayed on an electronic geographical map using Web-based GIS (WebGIS) technology. The employment of WebGIS facilitates the dynamic visual representation of the spatial information of the resource distribution on an electronic map. WebGIS is a new technology that combines the Internet and GIS. End users can search and analyze the GIS data intuitively on the Internet using browsers. Luo et al. (2001) propose a framework to provide a new model for WebGIS services in a network environment (Luo et al., 2001).

GSM is a digital cellular technology and the world's leading standard in digital wireless communications that is used worldwide. Short Messaging Service (SMS) is one of the non-voice data and messaging application in GSM and General Packet Radio Services (GPRS) is a GSM service for end-to-end packet switching. SMS is an older, simple and convenient way of sending information so long as they are text based where each message is limited to 160 characters. GPRS is a non-voice value added service that allows data (text, pictures and sound) to be sent and received across a mobile telephone network. GPRS is a packet switched "always on" technology supporting Internet Protocols (IP) with a theoretical maximum speed of up to 114 kbps which dial-up modem connection is not necessary(Ward et al., 2004). Typically, in GPRS based transmission, system can send more data and quicker.

\section{PROPOSED SYSTEM}

The intelligent system developed in this research could be divided into two parts, the system and central station. This mobile intelligent system mainly consists of three types of hardware components; namely, (i) RFID technology (RFID readers, antenna); (ii) GPS technology (GPS receiver); and (iii) GSM communication technology, therefore takes advantage of the respective strengths of each. Passive Ultra-High Frequency (UHF) band RFID tags will be used for identifying and monitoring the objects by the help of RFID reader which is connected to the system. GPS technology will be used for locating and positioning the equipment that transports 
the materials and the current location of objects. Collected data (ID, date, location etc.) retrieved from RFID readers and GPS is transferred via GSM technology in the form of GPRS or SMS. Therefore, data collection is done continuously, autonomously, and it is not influenced by the conditions on-site, such as line of site and weather. The central station consists of two servers, application server and database server. Application server is a monitoring station, where accurate position of each construction resource is displayed on a GIS map, and the information of each resource can be queried. A schematic model and a photo of the system are shown in figure 2 .
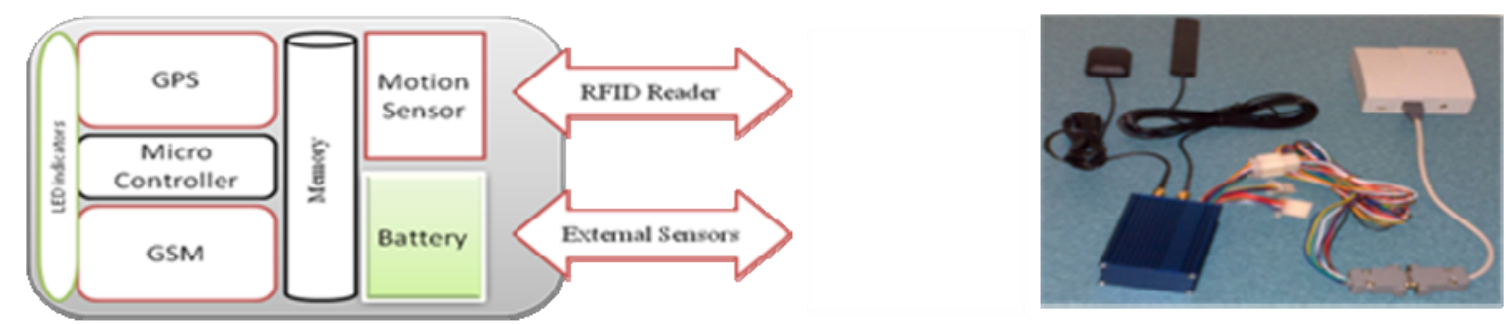

Fig. 2 A schematic model and a photo of the intelligent system

In this approach, tracking process begins with RFID tags that contain unique ID numbers which can be placed on any object (engineered-to-order/ materials) and all of the related information such as item specific information or instructions will be stored in databases which will be indexed with the same unique ID of objects. Suppliers will attach RFID tags to all objects such as materials and possibly some bulk materials which are to be delivered in unit sets. At the times of moving or picking up of any pieces, ID information of the piece is captured by the RFID reader and the location of the piece is read from a GPS receiver. The ID and location information of the piece is then sent to a database via GSM technology. Figure 3 illustrates the simple architecture of the integrated system using RFID, GPS, and GSM technology for automatic data collection in construction supply chain and logistics.

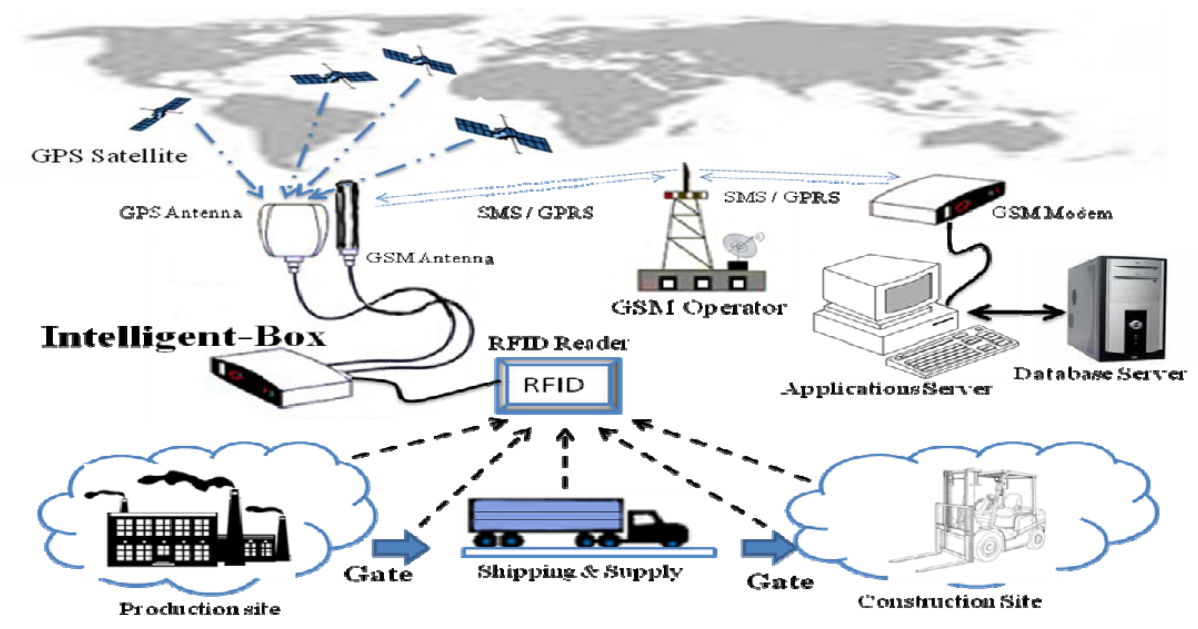

Fig. 3 Automatic data collection during production, shipping, and installation 
The delivery vehicle, the gates and some key workers should be equipped with a system. This intelligent system could be programmed to send back information via SMS when RFID reader or user defined sensors which are connected to the system receive new data, for example from uploaded component to the truck or detected data by sensors. Extremely heavy foliage or underground places like tunnels would cause the signal to fade to an extent when it can no longer be heard by the GPS or GSM antenna. When this happen, the receiver will no longer know its location and the in the case of an intelligent system application, the vehicle is technically lost and central office won't receive information from this system. In this case to locate vehicles inside GPS blind areas, intelligent system will use RFID reader to save tag-IDs in the way through the tunnel or parking -each tag-id shows a unique location- the device will store all information inside internal memory as a current position, and the system will send unsent data to central office when network re-established. To give an accurate last point to locate vehicles driven in an area such as underground tunnels only GPRS should be used. A schematic model of supply chain management and control in construction is shown in figure 4.

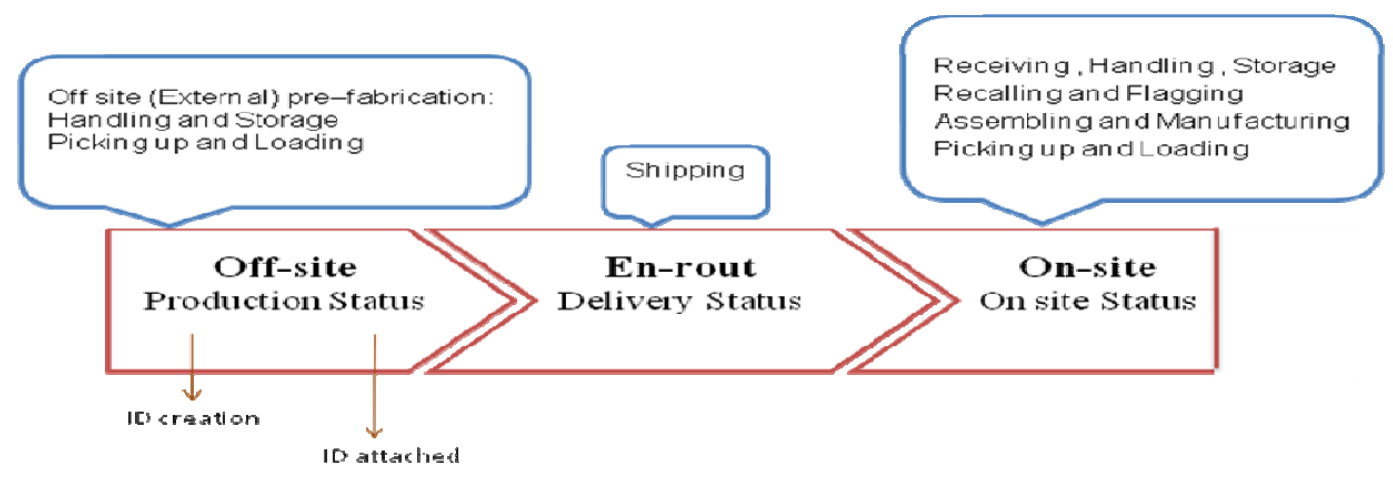

Fig. 4 Supply chain management and control schematic model.

The central station can get the current location of a materials and estimate the travel time of them before it arrives at a predetermined construction site by using functions in a GIS system. GIS facilitates the complete management and control of the system for tracking and monitoring the construction resource e.g. materials and equipments. Citing factors such as screen size for RFID reader, outdoor readability, battery power, physical unit size and robustness are important considerations in the selection of appropriate hardware for the construction site. To minimize the performance reduction of selected technology under harsh conditions (e.g., rain or possible impacts from different pieces of equipment) and while in contact with metal and concrete, RFID tags will be encapsulated or insulated.

\section{CONCLUSIONS}

The research is to develop an intelligent system in order to automate collecting data in construction supply chain and materials moving flow in logistics based on RFID, GPS and GSM 
technology. The system is consists of mobile system and server side. Three type of hardware in mobile, pervasive and ubiquitous system are GPS combination with RFID in conjunction with GSM and application and database servers are central station. The aim of this research is to identify opportunities for applying advanced tracking and data storage technologies in construction supply chain management and to develop a model that explores how these technologies can be used in construction phase. Approached intelligent system permits real-time control enabling corrective actions to be taken which leads to reduction in costs and handling unnecessary traffic of resource. In addition, up-to-date information is available. The authors believe that full automation of the supply chain in construction industry can increase the efficiency and quality of the operation and lead to reductions in project costs and time.

\section{REFERENCES}

AKINCI, B., KIZILTAS, S., ERGEN, E., KARAESMEN, I. Z. \& KECELI, F. 2006. Modeling and analyzing the impact of technology on data capture and transfer processes at construction sites: a case study. Journal of Construction Engineering and Management, 132, 1148-1157.

ARBULU, R. J. \& TOMMELEIN, I. D. 2002. Alternative supply-chain configurations for engineered or catalogued made-to-order components: case study on pipe supports used in power plants. IGLC10. August 6-8, Gramado, Brazil.

BEHZADAN, A. H., AZIZ, Z., ANUMBA, C. J. \& KAMAT, V. R. 2008. Ubiquitous location tracking for context-specific information delivery on construction sites. Automation in Construction, 17, 737 748.

CALDAS, C. H., TORRENT, D. J. \& HAAS, C. T. 2006. Using Global Positioning System to Improve MaterialsProcessing on Industrial Projects. Journal of Construction Engineering and Management, 132 (7), 741-749.

CHOPRA, S. \& MEINDL, P. 2001. Supply Chain Management: Strategy, Planning, and Operation, Prentice Hall, Inc., NJ.

ERABUILD 2006. Review of the current state of Radio Frequency Identification (RFID) Technology, its use and potential future use in Construction

ERGEN, E., AKINCI, B. \& SACKS, R. 2007. Tracking and locating components in a precast storage yard utilizing radio frequency identification technology and GPS. Automation in Construction, 16, 354-367.

FURLANI, K. M. \& PFEFFER, L. E. 2000. Automated tracking of structural steel members at the Construction site. XVII International Symposium on Automation and Robotics in Construction (ISARC 2000). Taipei, Taiwan.

GASSEL, F. V. \& JANSEN, G. 2008. A Simulation Tool for Radio Frequency Identification Construction Supply Chains. In: The 25th International Symposium on Automation and Robotics in Construction (ISARC 2008), Vilnius, Lithuania. 64-68.

JANG, W. S. \& SKIBNIEWSKI, M. J. 2007. Wireless sensor technologies for automated tracking and monitoring of construction materials utilizing Zigbee networks. ASCE Construction Research Congress: The Global Construction Community. Grand Bahamas Island,.

JASELSKIS, E. J. \& EL-MISALAMI, T. 2003. Implementing radio frequency identification in the construction process. Journal of Construction Engineering and Management, 129, 680-688. 
JASELSKIS, E. J., R., A. M., JAHREN, C. T., RODRIGUEZ, Y. \& S., N. 1995. Radio frequency identification applications in construction industry. Journal of Construction Engineering and Management, 121, 189-196.

KANEKO, T., HAMADA, K. \& KONDO, T. 2007. Development of Construction Logistics System Using Radio Frequency Identification. 24th International Symposium on Automation \& Robotics in Construction (ISARC 2007). I.I.T. Madras, Kerala, India.

LAHIRI, S. 2005. RFID Sourcebook, Prentice Hall.

LANDT, J. 2005. The history of RFID. IEEE Potentials, 24, 8-11.

LU, M., SHEN, X. \& CHEN, W. 2009. Automated Collection of Mixer Truck Operations Data in Highly Dense Urban Areas. Journal of Construction Engineering and Management, 135 (1), 17-23.

LUO, Y., WANG, X. \& XU, Z. 2001. Design of a framework for multi-user/application oriented WEBGIS services. In: International Conference on Computer Networks and Mobile Computing, 151-156.

MAJROUHI SARDROUD, J., LIMBACHIYA, M. C. \& SAREMI, A. A. 2009. An Overview of RFID Application in Construction Industry. Third International RFID Conference, 15-16 August. Tehran, IRAN.

MAJROUHI SARDROUD, J., LIMBACHIYA, M. C. \& SAREMI, A. A. 2010. Ubiquitous Tracking and Locating of Construction Resource Using GIS and RFID. 6th GIS Conference \& Exhibition, GIS 88, 6 January. Tehran, IRAN.

NARESH, A. L. \& JAHREN, C. T. 1997. Communications and Tracking for Construction Vehicles. Journal of Construction Engineering and Management, 123, 261-268.

NAVON, R. \& BERKOVICH, O. 2005. Development and on-site evaluation of an automated materials management and control model. Journal of Construction Engineering and Management, 121, $1328-1336$.

NAVON, R. \& GOLDSCHMIDT, E. 2002. Monitoring labor inputs: automated-data-collection model and enabling technologies. Automation in Construction, 12, 185-199.

NAVON, R. \& SHPATNITSKY, Y. 2005. Field experiments in automated monitoring of road construction. Journal of Construction Engineering and Management, 131(4), 487-493.

PEYRET, F., BETAILLE, D. \& HINTZY, G. 2000. High-precision application of GPS in the field of realtime equipment positioning. Automation in Construction, 9, 299-314.

SIMCHI-LEVI, D., KAMINSKY, P. \& SIMCHI-LEVI, E. 2000. Designing and Managing the Supply Chain Concept, Strategies, and Case Studies, McGraw-Hill, Inc., NY.

SONG, J., HAAS, C. T., CALDAS, C., ERGEN, E. \& AKINCI, B. 2006a. Automating the task of tracking the delivery and receipt of fabricated pipe spools in industrial projects. Automation in Construction 15, 166 - 177.

SONG, J., HAAS, C. T. \& CALDAS, C. H. 2006b. Tracking the Location of Materials on Construction Job Sites. Journal of Construction Engineering and Management, 132, 911-918.

TORRENT, D. G. \& CALDAS, C. H. 2007. Field Experiments of an Automated Materials Identification and Localization Model. ASCE International Conference on Computing in Civil Engineering, Sponsored By Technical Council on Computing \& Information Technology of the American Society of Civil Engineers). Pittsburgh, Pennsylvania, USA

WANG, L. C., LIN, Y. C. \& LIN, P. H. 2007. Dynamic mobile RFID-based supply chain control and management system in construction. Advanced Engineering Informatics, 21, 377-390.

WARD, M., THORPE, T., PRICE, A. \& WREN, C. 2004. Implementation and control of wireless data collection on construction sites. Electronic Journal of Information Technology in Construction, (ITCon), 9, 297-311. 